\title{
Validity of Metaphor Translation in Fortress Besieged in light of
}

\section{Relevance Theory}

\author{
Xu Yanting ${ }^{1, a}$ \\ ${ }^{1}$ Jiangxi college of foreign studies,NanChang,330099, China \\ axuyanting@yeah.net
}

Keywords: Fortress Besieged; relevance theory; metaphor translation

\begin{abstract}
.
Relevance theory is put forward by the scholars Sperber \& Wilson and it is the foundation of cognitive linguistics. In the process of translation, both two kinds of language which has relevance depends on the two factors: one is contextual efforts; the other is processing efforts. Translators need to find the maximum relevance for the best communicative efficacy. Professor Zhang Yanchun noted relevance theory that the validity of translation is reached on the condition whether it has embodied communicators' intentions and satisfied acceptors' expectation or not. And the so-called successful translation refers to the validity of translation.
\end{abstract}

\section{Introduction}

In short, translation is just translating the intention of the authors. With the proposition of relevance theory by Dan Sperber \& Deirdre Wilson and making translation relate to the relevance theory by their students E. A. Gutt in his doctorate thesis Translation and Relevance Cognition and Context, relevance theory has opened a great gate for translation research in which finding relevance to the best degree between different languages provides translators and scholars a useful way to achieve their goals in translating arena.

\section{A Case-study of Validity of Metaphors in Fortress Besieged in Light of Relevance Theory}

As a great number of metaphors exist in Fortress Besieged which bear the creative ways of thinking. For the better metaphor translation, we are going to study the validity of metaphors of this novel in a more detained and specific way in light of relevance theory.

(1) 原文: 有他, 菜可以省一点; 看见他那个四喜丸子的脸, 人就饱了。

译文: If he is, they can save the food. Just looking at that four-happiness meatball face of his will make people feel full.

Four-happiness meatball is a traditional Chinese dish made with the chopped meat. Generally few people would compare face with the meatball. Yet Qian Zhongshu has noticed the seemingly irrelevant things have the similarity in their appearance: round, big and even fatty. When taking the first sight of the comparison, readers will feel amazed then smile with an understanding. The meatball face is a fresh way of expression and would take readers much processing efforts to comprehend but the meatball is a common food in people' daily life so both source audience and target audience would find it easy to connect face with meatball so that the optimal relevance could be kept.

From the perspective of relevance theory, we could analyze the validity of the metaphor in a more 
specific and scientific way. That is to apply the translational constituents of inferential modes stated by professor Zhao Yanchun which is the standard to evaluate translational validity or more exactly the unification of validity and fidelity. Zhao holds that the best translation with high validity is produced when the conventional meaning of univalent translation constitute and the short-circuited conversational implicature of bivalent translation constitute or the literal sense of translation constitute of bivalent translation constitute. In the example one, 四喜丸子 in Chinese bears the conventional meaning. That is to say it has the short-circuited conversational implicature in the source text people can directly infer the connotation of the expression without any inferential efforts so does the target audience who can infer from his cognition and acquire the conversational implicature though there is no correspond short-circuited implicature in the target langage but the ostensive translation or the literal translation has been employed in the metaphor so target audience can get the idea of the metaphor. Thus source audience and target audience reach the communicative efficacy in the same level and translational validity is achieved. Since it is the literal translation from source language to target language fidelity has also been met.

(2) 原文: 董斜川道: “好,好, 虽然 ‘马前泼水’, 居然 ‘破镜重圆’,慎明兄将来的婚姻一定离合悲 欢，大有可观.”

译文: Tung Hseih-ch’uan said, “well, now. Though ‘water was poured before the horse’, still the 'broken mirror was made round again' Shen-ming's future marriage will certainly be full of vicissitudes. It should be worth watching.”

In this conversation, Mr. Qian has employed two idioms from Chinese ‘马前泼水' and ‘破镜重 圆'. The plot goes when Shen-ming is so delighted because it is the first time that a beautiful lady discusses something about ' heart' with him. Thus he is so excited that his glasses fall down into the cup of milk and fortunately his glases has not been broken. In order to tease him, Tung Heih-ch'uan apply the two Chinese idioms to describe this little incident.

Viewing from relevant translation, idioms have the conventional meaning and short-circuited conversational implicature so the idiom '马前泼水' and ‘破镜重圆' can be understood by the source audience immediately. And for the target audience, the communicative efficacy has also been achieved in the same way with the source audience since the idioms are translated literally with annotation to show their cultural connotation. In this point, target audience can grasp the meaning of the Chinese idioms with no inferential efforts and the best relevance is distinctively obvious. The literal translation of the two idioms reveals the accomplishment of literal sense of bivalent translation constituent which suits the standard of relevant translation so the validity of this metaphor has been reached. However, here the translation of the idioms fail to complete the goal of faithfulness or fidelity as the short-circuited conversational implicature of bivalent translation constituent has not been translated from the target language. That is to find the correspond idioms in the target language which are showing the characteristics of similarity in the form and style. Here the translation is just explanatory interpretation of the idioms without any beauty in language and form. Therefore fidelity can not be satisfied in this translation though validity is reached already.

（3）原文: 假使订婚戒指是落入圈套的象征, 纽扣也是扣留不放的预兆.

译文: If the engagement ring were a symbol of the trap one had fallen into, button-sewing was an omen of being tied up.

Example three has two analogies. One is to compare the engagement ring with the trap as both them is similar in the shape and it implies falling into love with somebody is just like falling into the trap of somebody because you have belonged to someone else. The other is to compare the button-sewing to the omen of being tied up. In Chinese, 纽扣 and 扣留 share the same pronunciation in 扣 (being tied up) which has the connotation of fastening and retaining. In the 
cognitive environment of both Chinese and western audience, they would perceive the same assumption of the connection of engagement ring and the trap so here translator preserve the tenor and vehicle of the words and reach the best relevance between the target language and source language. The second comparison has some flaws in addressing the translation of fa.Though it is accurate in translating its conventional meaning but fails to translate the ingenious connection between the image of button-sewing and being tied up. Thus the optimal relevance has not achieved and communicative effect is not so successful.

From the aspect of the modes of relevant translation, the first comparison of the conventional meaning of univalent translation constituent is very clear for the source audience and target audience since they share the same cognition about the two things 戒指 and 圈套 and would infer the conversational implicature by themselves with little processing effort. And the phrase is obviously fall into the category of idiom so it has no the short-circuited conversational implicature but the literal sense of bivalent translation constituent is clearly stated so the first comparison reach the validity and so does the fidelity for it is translated literally and correspond to each other in form and connotation. In the second comparison, 扣子 and 扣留 is correctly translated thus its conventional meaning and literal sense of translation constituent is achieved so the validity of the phrase is reached. Yet it fails to realize the fidelity though it is exactly translated but 扣 in the tenor and vehicle share the same pronunciation which is the author's unique thinking to convey his thought. The translation has not encompassed the chic connection between the tenor and vehicle.

(4) 原文: 科学家像酒, 越老越可贵; 而科学像女人, 老了便不值钱.

译文: Unfortunately, there is a word of difference between a scientist and science. A scientist is like wine. The older he gets, the more valuable he is, while science is like a woman. When she gets old, she is worthless.

The older scientists get the more honorable they are. Because the accumulation of experience is not merely from book just as people are inclined to seek medicine from the elder doctors for they are more experienced. Here the translation employs the wine as the vehicle which is the best image to express the implied meaning of scientist in the original text owing to the longer the wine has been stored the purer and sweeter the taste is. In the comparison of science and woman, science changes with each passing day and rapid development so it is a necessity that it needs to continuously advance. Science getting old is just like out of date with little worth. Comparing science to an old woman, like a worn-out yellow pearl, is of little worth, is very vivid and imagery. Translators save the tenors and vehicles of the two comparison of source text as both Chinese and western people hold the same view towards the interpretation of scientist and science that the elder scientist is more respectable and obsolete science is worthless at all. In their cognitive environment, comparing scientist to wine and science to the old woman can be understood with a certain inferential efforts that meets the goal of the best relevance.

Both the comparison of scientist and science realize translational validity. It is not only because they reach the optimal relevance but also in the perspective of inferential mode of relevant translation both Chinese and western people understand the conventional meaning in the same way so the conventional meaning of univalent translation constituent has been translated literally. And for the short-circuited conversational meaning or literal sense of translation constituent of bivalent translation, since scientist and science are just a phrase and so it does not carry the short-circuited conversational meaning in their conventional meaning but the literal sense of translation constituent and conventional meaning of the two comparison has been successfully translated. Therefore, the translational validity has been reached. Since source text and translated text is similar in form and connotation and style for it is translated by the means of literal translation thus the translational 
fidelity is also achieved.

\section{Translating the Conventional Meaning of Bivalent Translation Constituents of Metaphor}

In the view of the theory of relevant translation, translating the conventional meaning of bivalent translation constituent of metaphor would be another best way to a valid and faithful translation. Comparing to the translation of short-circuited conversational implicature, the translation of conventional meaning of bivalent translation constituent is harder to be done yet there are still some examples to demonstrate this kind of translation. Examples are cited from Fortress Besieged :

例(1) 原文: “明天我教爸爸罚你对祖父祖母的照相三䟜九吒首.”

译文: “Tomorrow I’ll have Papa make you kneel three times and kowtow nine times before photographs of my grandparents as the penalty.”

例(2) 原文: 真的是金榜题名, 洞房花烛，要算得上双喜临门了.

译文; A case of having your name on the golden rolls and figured candles in the nuptial chamber. Note: to be listed among successful candidates in the government examination.

例(3) 原文: 那真是以后天发展先天,锦上添花了.

译文: For a woman to study political science is really developing the innate through the acquired; it is as superfluous as adding flowers to embroidery.

例(4) 原文: 自信这席话委婉得体, 最后那一段尤其接得天衣无缝.

译文: He was confident his little speech was tactful and proper, especially the last part, which has been sewn together as flawlessly as "a divine suit of clothes”.

In the example one, 三跪九拜( make sb. kneel three times and kowtow nine times) is the traditional etiquette between the emperor and his subjects in the ancient Chinese dynasties. The folks are employing the way as the expression to pay pious respect to the Buddha and offer sacrifice to their ancestors. That is to make one kneels three times and each kneel down is followed by the kowtow three times. In this case, we can see that 三趾九拜 has no the corresponsive image in the target language and impossible to have one since it is the Chinese special cultural phenomenon and is unique to show the characteristics of a nationality so translators resort to the translation of the conventional meaning of bivalent translation constituent. In this way of translation, even there is no short-circuited conversational implicature but through the means of the translation of conventional meaning, target audience can grasp the main idea of what the author of the original text try to convey in the same way as the source audience does and achieve the same communicative intention at last. Therefore, the translational validity of the metaphor has been quite good for it has found the best relevance in the process of inference.

In the example two, either for the preservation of the characteristics of Chinese cultural images or no short-circuited conversational implicature in English, the transliteration is the embodiment of the conventional meaning of bivalent translation constituent.Here 金榜题名 and 洞房花烛 are Chinese unique cultural images and demands the necessity of saving the beauty of cultural traits should be the important concern for the translators so translating the conventional meaning of bivalent translation constituent is best method of translating the Chinese idioms. Therefore the conventional meaning of 金榜题名 and 洞房花烛 are translated as a case of having your name on the golden rolls and figured candles in the nuptial chamber and plus the annotation. In Chinese culture , there are four great joyous occasions in one's life: a good rain after a long drought, to meet an old friend in a distant land, and to have your name on the golden rolls and figured candles in the nuptial chamber. So clearly we can conclude that the two great joyous occasions take place at the 
same time or we can call it 双喜临门 in Chinese. Therefore the conventional meaning plus the annotation have indeed transferred the cultural factors in it and a valid translation of metaphor for the implied meaning or the author's intent has been truly exposed to the target audience.

In the example three, 锦上添花 is the Chinese idiom and indicates to sew the flowers to the brocade implying getting better and better and becoming more beautiful and beautiful. Here in the translated text, it has been translated as superfluous as adding flowers to embroidery which has conveyed the conventional meaning of bivalent translation constituent by revealing the Chinese image literally. Thus it can be seen that the implication of this Chinese cultural image has been to shown and so does the author's intent of original text. Target audience can conceive the metaphor with his cognition and the help of the translation with little inferential efforts since the translation is valid in some way and also achieve the fidelity of translation so turning to the conventional meaning of bivalent translation constituent is a key to a successful communication.

In the example four, 天衣无缝 is where metaphor lies in. 天衣无缝 or we can say 'as flawlessly as a divine suit of clothes' indicates the divine suits wore by fairy maiden which is no crevice at all. Now it indicates to compare things that are extremely perfect and natural without any traces and here it is applied to demonstrate the content of the letter is absolutely wonderful with the persuasive words and expressions. From this point, the conventional meaning of the metaphor has been clearly displayed so as the implied meaning of the metaphor. As a result, we can say that the best relevance is highlighted through the means of translation of conventional meaning of bivalent translation constituent and the translational validity of the metaphor is reached. And for the accuracy of the metaphor translation, it is obviously stated to the target audience in meaning, form and the traits so the fidelity of the metaphor translation is realized already.

\section{Conclusion}

A translated text of metaohor is produced with the unification of validity and fidelity. These has been clearly discussed in the above analysis in Fortress Besieged.

\section{References}

[1]Aristotle. Rhetoric and Poetic [M]. NewYork: The Modern Library, 1954.

[2]Chesterman,Andrew. Memes of Translation [M].Amsterdam: Benjamins, 1997.

[3]Ch'ien, Chung-shu. Fortress Besieged, trans. By Kelly, Jeanne \& Mao, Nathan K. Beijing: Foreign Language Teaching and Research Press, 2003.

[4]Jeanne Kelly \& Nathan K Mao. Fortress Besieged [ Z] . Indiana University Press,1979.

[5]Lakoff, George andM. Johnson. Metaphors We Live By [M]. Chicago: University of

Chicago Press, 1980. 